\title{
ENSINO E TECNOLOGIA: DIÁlOGOS POSSÍVEIS ENTRE O ESTÁGIO CURRICULAR OBRIGATÓRIO E A FORMAÇÃO DISCENTE
}

\author{
TEACHING AND TECHNOLOGY:POSSIBLE DIALOGUES BETWEEN THE \\ COMPULSORY CURRICULAR TRAINEESHIP AND THES
}

DOI: http://dx.doi.org/10.23926/RPD.2526-2149.2018.v3.n2.p720-739.id135

\section{Eliza Adriana Sheuer Nantes \\ Doutorado em Estudos da Linguagem (UEL). \\ Professora da Universidade Norte do Paraná (UNOPAR). elizanantes@gmail.com}

\section{Maria Júlia Carneiro Giraldes \\ Doutorado em Estudos da \\ Linguagem (UEL). \\ Professora no Departamento de Ciência da Informação (UEL). \\ giraldes@uel.br}

\section{Themis Farias de França Desiderio} Professora de Libras (UniMontes). themis_farias@hotmail.com

\section{Ana Paula Pinheiro da Silveira \\ Doutorado em Estudos da Linguagem (UEL). Professora da Universidade Tecnológica Federal do Paraná (UTFPR) elizanantes@gmail.com}

Resumo: Este trabalho interliga os resultados da pesquisa "A formação de professores em cursos de licenciatura $\mathrm{EaD}$ : do aprender com tecnologia ao ensinar com tecnologia", atrelado à linha de pesquisa "Ensino de Linguagens e suas Tecnologias", cujo objetivo é investigar o impacto das novas tecnologias na formação discente, mais especificamente no Estágio Curricular Obrigatório, dos alunos de Letras, na modalidade Ensino Presencial Conectado. Para tanto, procedeu-se uma pesquisa qualitativa, realizada junto aos alunos de graduação dos últimos períodos do curso de Letras de uma universidade particular do estado de Minas Gerais, utilizando-se o questionário, enquanto instrumento de pesquisa. A ancoragem teórica seguiu a linha epistemológica do multiletramento enquanto prática social, tendo em vista a necessidade de novas práticas de leitura, dentro do contexto tecnológico vigente. Os dados apontaram para uma consciência dos discentes sobre a necessidade do uso da tecnologia na esfera escolar, porém a enunciação dos sujeitos indicou, também, que ainda há falta de saberes sobre como transpor o construto teórico na prática.

Palavras-chave: Ensino. Educação a Distância. Formação de Professor.

\begin{abstract}
This work connects the results of the research that was carried out in the Project "Teacher education in undergraduate courses distance learning: of learning with technology while teaching with technology", linked to the line of research "Teaching of Languages and their Technologies", which aims to investigate the impact that new technologies have on students formation, more specifically in Mandatory Curricular Practicum for Letters students in Connected Classroom Teaching. For this purpose, a qualitative research was carried out with students who were in the last semesters of the Letters Course in a private university in the state of Minas Gerais. A questionnaire was used as an instrument for the research. The theoretical references followed an epistemological basis of multiliteracy as a social practice and the data showed that students are conscious about the necessity of using technology at schools. Nevertheless, their enunciation also indicated that they still do not know how to put this theory in practice.
\end{abstract}

Keywords: Education. Distance Education. Teacher Education. 


\section{INTRODUÇÃO}

A comunicação do ser humano, segundo a visão bakhtiniana, ocorre por meio da interação social. Logo, se há compreensão, há interação (BAKHTIN, 2010). Assim, dialogicamente, o homem constitui-se como sujeito na relação com o outro, utilizando a linguagem enquanto instrumento que lhe permite trocar informação e, dessa forma, apropriarse de novos conceitos. Tal movimento - dialógico e dialético - manifesta-se por meio da interação, e esta é moldada/adequada, segundo às situações discursivas presentes nas diversificadas esferas de atividade humana.

Mediante o exposto, considerando o homem encontrar-se inserido em uma cultura multi/pluri letrada e sendo um dos papéis da escola a inserção desse indivíduo no mundo do trabalho, a abordagem dos gêneros contemplando os multiletramentos é premente para que o sujeito possa adquirir e/ou desenvolver uma competência linguística satisfatória na era da cibercultura (LÉVY, 1996).

A partir desse entendimento, o objetivo deste trabalho é investigar o impacto das novas tecnologias na formação discente dos alunos de Letras, na modalidade Ensino Presencial Conectado. Logo, premente se faz o estudo do significado de letramento e multiletramento, que difere da alfabetização em si, pois se entende que o sujeito, além de saber ler e escrever, também precisa responder adequadamente às demandas sociais da leitura e da escrita, ou seja, integrarse efetivamente ao seu contexto social, e isso inclui a questão do letramento digital.

Então, para investigar se o aluno do Curso de Letras, da modalidade Ensino Presencial Conectado, está apropriando-se das novas tecnologias em sua prática, mais especificamente, se faz uso constante dessas novas tecnologias, algumas apontadas pelo curso que frequenta, organizamos o presente trabalho da seguinte forma: (a) inicialmente, versamos sobre o construto teórico de nossas pesquisas; (b) a seguir, apresentamos a metodologia de pesquisa adotada, com os respectivos materiais e métodos; (c) a ação seguinte consiste na apresentação analítica dos dados coletados; (d) por fim, tecemos nossas considerações finais e as referências pesquisadas.

\section{REFERENCIAL TEÓRICO}

A cada momento surgem novas práticas e habilidades de leitura e escrita associadas ao contexto sociocultural, e, juntamente, diferentes letramentos, que, por sua vez, são fenômenos amplos de leitura e escrita, indo além da alfabetização, ou seja, da simples decodificação do texto. 
Segundo Soares (2004, p.47) a questão da alfabelização e do letramento "são duas ações distintas, mas não inseparáveis, ao contrário: o ideal seria alfabetizar letrando, ou seja, trata-se de "ensinar a ler e escrever no contexto das práticas sociais da leitura e da escrita", de tal forma que culmine com um indivíduo que "se tornasse, ao mesmo tempo, alfabetizado e letrado.

A partir desse raciocínio, entendemos que a alfabetização e o letramento devem andar lado a lado no processo de uma base sólida de aprendizagem, que busca o prazer pela leitura e a formação de cidadãos capazes de fazer sua própria interpretação do mundo, deixando de lado a mecanização da leitura e da escrita. Por isso, apropriar-se das técnicas e do uso dos sistemas, códigos e signos linguísticos na leitura e na escrita são necessários.

Contudo, não basta somente decodificar, deve-se letrar, considerando que a alfabetização tem de estar ligada às práticas de leitura e escrita presentes no contexto sóciohistórico, criando-se, assim, uma relação efetiva com estas. A respeito do letramento, Soares (2004, p.17) afirma ser “o estado ou condição que assume aquele que aprende a ler e escrever", por conseguinte, está implícito "a ideia de que a escrita traz consequências sociais, culturais, políticas, econômicas, cognitivas, linguísticas, quer para o grupo social em que seja introduzida, quer para o indivíduo que aprenda a usá-la”.

Tfouni (1995, p. 20) esclarece que "o letramento focaliza os aspectos sócio-históricos da aquisição de um sistema escrito por uma sociedade". Assim, letramento seria o resultado ou consequência do processo de alfabetização, em uma intersecção com os processos sóciohistóricos de leitura e escrita adquiridas por um grupo social ou indivíduo, fruto dos resultados das interações sociais em dado tempo, inserido em dado espaço e com determinados sujeitos que interagem entre si

Nessa vertente, as atuais discussões sobre a teoria de letramento conduzem-nos a novos desafios, diante da variedade das práticas letradas do mundo contemporâneo, que se manifestam concretamente via múltiplos gêneros discursivos, surge o termo multiletramento, visto ser mais apropriado e condizente com a nossa sociedade contemporânea.

O conceito de multiletramento surgiu em 1996, com um grupo de estudiosos, denominado Grupo de Nova Londres. Segundo Rojo e Moura (2012), com o aparecimento das novas tecnologias, houve a facilitação do acesso à comunicação e à informação. Por conseguinte, fazia-se necessário a escola atentar para esses novos letramentos de caráter multimodal, os quais apresentam uma multiplicidade de linguagens, semioses, com pluralidade e diversidade cultural. 
Com o surgimento das novas tecnologias de comunicação e informação, fez-se necessário um novo olhar sobre o multiletramento, condizente à nova realidade social. Rojo e Moura (2012, p. 13) pontuam que "diferentemente do conceito de letramentos (múltiplos), que não faz senão apontar para a multiplicidade e variedade das práticas letradas, valorizadas ou não nas sociedades em geral" a definição do termo "aponta para dois tipos específicos e importantes de multiplicidade presentes em nossa sociedade". $\mathrm{Na}$ sequência do texto, são apresentadas essas especificidades como parte de um contex to urbano e contemporâneo, sendo "a multiplicidade cultural das populações e a multiplicidade semiótica de constituição dos textos por meio dos quais ela se informa e comunica".

Há de se considerar que, nos dias atuais, na era tecnológica, a comunicação, frequentemente, é feita por computador e internet, causando grandes mudanças nas formas de letramento. Isso faz surgir novas “formas de mudanças na interação entre escritor e leitor, entre escritor e texto, entre leitor e texto e até mesmo, mais amplamente, entre o ser humano e o conhecimento" (SOARES, 2002, p.151). Esse fenômeno é global e remete a um novo estado ou condição na prática de leitura e escrita de quem o utiliza.

Nessa esteira, há o letramento digital inserido na Cibercultura, em que o leitor é, também, autor, e não há mais a necessidade, como no texto impresso, de seguir uma linearidade. Para ser um letrado digital, deve-se ir além do conhecimento técnico e responder adequadamente às demandas sociais que envolvem a utilização dos recursos tecnológicos e da escrita no meio digital.

Sobre letramento digital Carmo (2003, p. 1) esclarece ser a "habilidade para construir sentido a partir de textos multimodais", e explica-se o que seriam estes textos, ou seja, aqueles que "mesclam palavras, elementos pictóricos e sonoros numa mesma superfície. Inclui também a capacidade para localizar, filtrar e avaliar criticamente informações disponibilizadas eletronicamente. Nesse contexto, é preciso saber realmente manusear as regras da comunicação em ambiente digital e ter competência crítica para selecionar as informações, visto a forma de comunicação e interação diferirem da antiga forma de texto linearmente construído.

Silva (2012) enfatiza que, no panorama do letramento digital,

ser letrado é poder interagir da maneira descrita pelos autores em ambientes digitais, isto é, realizando práticas de leitura e escrita que diferem das práticas tradicionais. É saber pesquisar, selecionar, utilizar as diversas ferramentas disponíveis para cumprir propósitos variados, é se relacionar com seus pares, aprender constantemente, construir, transformar, reconstruir, exercer autoria, compartilhar conhecimento etc., sempre utilizando os recursos da Web, quer para sua vida pessoal ou profissional (SILVA, 2012, p. 14). 
A tela do computador, portanto, configura-se como um novo espaço, um meio inovador para a leitura e a escrita, ferramenta tecnológica criada pela sociedade, que utiliza e dá sentido a esse novo modelo de comunicação e interação que requerem novas habilidades na construção de textos conectados a outros, lidos de forma multilinear, multissequencial, por meio de hipertextos e links, elementos pictóricos e sonoros, enfim, um mundo de muitas possibilidades (SOARES, 2002).

Ainda sobre essa temática, Xavier (2015, p. 04) assevera que "a principal condição para a apropriação do letramento digital é o domínio do letramento alfabético pelo indivíduo". Isso nos leva ao requisito essencial, ou seja, precisamos ter uma alfabetização de qualidade interligada ao letramento, posto não haver letramento digital pleno sem se ter aprendido a ler, escrever e interpretar criticamente, ou seja, sem interagir, sentir prazer, emocionar-se, informarse, enfim, (re)descobrir-se com a leitura. É estabelecer pontes entre o letramento rumo ao multiletramento. A respeito do multiletramento, Rojo e Moura (2012) elucidam:

[...] trabalhar com multiletramentos pode ou não envolver (normalmente envolverá) o uso de novas tecnologias da comunicação e de informação ("novos letramentos"), mas caracteriza-se como um trabalho que parte das culturas de referência do alunado (popular, local, de massa) e de gêneros, mídias e linguagens por eles conhecidos, para buscar um enfoque crítico, pluralista, ético e democrático — que envolva agência de textos/discursos que ampliem o repertório cultural, na direção de outros letramentos (ROJO; MOURA, 2012, p. 8, grifo dos autores).

Tais proposições direcionam-nos ao desenvolvimento tecnológico crescente. Nele, a leitura e a escrita são feitas usualmente, por meio dos novos meios tecnológicos, via computador e suas respectivas ferramentas tecnológicas, tais como, a internet e os softwares, que colaboram para a produção e a visualização de novas práticas virtuais de comunicação e informação. Em virtude disso, surge um novo tipo de sujeito letrado, capaz de interagir e produzir sentidos, sendo ele o autor de sua própria história, editando, alterando e, até, publicando no ciberespaço (LÉVY, 1996).

Esse novo leitor encontra, na internet, múltiplos gêneros discursivos, com novos elementos e características do meio cultural e social, criados ou hibridizados, a partir das mídias digitais emergentes, como e-mail, as redes sociais, Facebook, chats, blogs, Twitter e vários outros comunicadores tecnológicos. Certamente, isso permite ao sujeito deixar de ser um mero observador, para ser um produtor ativo, principalmente se atender aos requisitos do letramento digital, que, ao contrário dos gêneros impressos de características lineares e sequenciais, em que o leitor assumia um papel mais passivo, propicia ao leitor estar um papel bem mais ativo na construção do seu saber. 
Isso posto, diferentemente dos gêneros impressos, as leituras digitais apresentam novas formas de textos, por exemplo, os hipertextos que permitem uma leitura mais flexível, por ser composta de uma variedade de links. Corroboramos o proposto por Lévy (1996, p. 38), no tocante à leitura na virtualidade, pois o autor destaca que enquanto "dobramos o texto sobre si mesmo, produzindo assim sua relação consigo próprio, sua vida autônoma, sua aura semântica, relacionamos também o texto a outros objetos", estendendo-se essa interconexão, inclusive, "a outros discursos, a imagens, a afetos, a toda a imensa reserva flutuante de desejos e de signos que nos constitui.

Com efeito, o hipertexto, além de propiciar ao leitor a pesquisa e a publicação de textos, dá poder de direção à leitura. Xavier (2004, p. 171) explica que o hipertexto pode ser entendido como uma "forma híbrida, dinâmica e flexível de linguagem que dialoga com outras interfaces semióticas, adiciona e condicionam à sua superfície formas outras de textualidade".

Assim, considerando ter a escola como objetivo um dos objetivos que "todos sejamos cidadãos capazes de ler e compreender um texto em qualquer circunstância, independentemente do gênero a que ele pertença" (NANTES, 2009, p. 01), entendemos ser de responsabilidade desta oferecer um ambiente favorável à leitura dos textos em todos suportes, incluindo o midiático. Justificamos tais proposições por defendermos que quanto mais o aluno tiver convivência com um bom acervo literário e melhor direcionamento para a leitura, mais preparado para se inserir nos meios sociais estará, pois, para se efetivar o letramento, o aluno terá de, além de saber ler, saber o significado do lido, enfim, compreender os sentidos presentes no texto em suas múltiplas semioses.

Então, o processo de letramento literário está muito além de apenas ler por ler: deve ser compreendido de forma integral. Nantes (2009, p. 01) afirma que "vivemos em uma sociedade letrada, na qual dominar a leitura e reconhecer os sentidos do texto é sinônimo de poder”. E acrescenta: "o que nos faz ler e construir significados dependerá da nossa capacidade de compreender ou não estes textos". Logo, esse é o caminho para termos leitores literários reflexivos e leitores ativos.

Como já postulado, entendemos que as novas práticas de leitura, envolvendo as multimodalidades, são fatores relevantes para melhorar o acesso à leitura, oferecendo ao aluno as ferramentas tecnológicas atuais, uma vez que faz parte do seu cotidiano. Como advertem Rampazzo et al. (2014, p.63):

[...] temos a geração $\mathrm{Z}$, que podemos caracterizar como todas as pessoas nascidas a partir de 1995 até os dias de hoje, são os conhecidos "nativos digitais puros". Sabem 
por quê? Nasceram e vivem "conectados" às mais modernas tecnologias existentes: Internet, banda larga, wi-fi, mp20..., celulares, ipod, ipad, netbook, notebook etc. (RAMPAZZO et al., 2014, p. 63, grifos dos autores).

Mesmo diante desse contexto, entendemos fazer-se necessário que haja uma orientação - tanto para o professor como para o aluno - sobre as possíveis formas de utilização das novas ferramentas tecnológicas, a fim de haver o desenvolvimento da capacidade de leitura digital, o que culmina com o adequado letramento propriamente dito.

\section{Materiais e Métodos}

A pesquisa caracteriza-se como qualitativa e, de acordo com Cruz (2009), a pesquisa qualitativa preocupa-se em compreender um fenômeno específico, considerando o contexto. Optou-se pelo instrumento de pesquisa sendo o questionário para a coleta de dados, tendo em vista as asserções de Fregoneze et al. (2014, p. 76) que pontuam a possibilidade dele "ser elaborado a partir dos objetivos propostos para a pesquisa", podendo contar questões abertas e fechadas, como é o caso dessa pesquisa na qual foram elaboradas 16 questões nesses moldes.

O lócus da pesquisa foi uma sala de aula de graduação do curso de Letras dos $5^{\circ}$ e $6^{\circ}$ períodos, de uma universidade particular do estado de Minas Gerais, tendo como sujeitos alunos que fizeram o Estágio Curricular Obrigatório. Em um universo de 30 sujeitos, após contextualização do objetivo do estudo e garantia de anonimato, 16 concordaram em participar.

Importante destacar: (a) antes de os alunos terem ido a campo, para o Estágio Curricular Obrigatório, tiveram a disciplina de Leitura e Produção de Textos II, que abordou os gêneros discursivos, em múltiplas esferas, chegando ao multiletramento e aos gêneros multimodais; (b) a disciplina Ensino e Tecnologia, contemplou, em seu conteúdo programático, a exploração da tecnologia, enquanto ferramenta, a ser utilizada na escola; (c) houve a indicação de que os estagiários, quando chegassem na esfera escolar, procedessem a um mapeamento dos recursos existentes, e, com a aplicação do questionário, buscamos identificar se os atores envolvidos alunos-estagiários, agentes-chave desse processo - apropriaram-se dos conceitos estudados no curso de Letras.

Dentre as 16 questões que compõe o instrumento (anexo 1), selecionamos apenas 7, por uma questão de recorte da temática a que nos propomos discutir neste momento. Para tanto, foi necessário movimentar um conjunto de procedimentos metodológicos buscando uma intersecção entre teoria e dados oriundos da pesquisa. De posse deles, sintetizamos as ações em: dado coletado > categorização $>$ tratamento dos dados/enunciações $>$ análises. 


\section{Resultados}

$\mathrm{Na}$ abordagem de natureza qualitativa, organizamos as enunciações dos sujeitos seguindo a categorização por unidade temática, de forma que permitisse agrupar por respostas similares, conforme Bakhtin (2010), assim, elegemos as percepções sobre: concepção de multiletramento; impacto das novas tecnologias na prática docente; recursos tecnológicos ou tipos de ambientes disponíveis na escola na qual realizaram o estágio; recursos utilizados; visão sobre o preparo do professor para usar a tecnologia em sala de aula.

Iniciamos a análise mapeando a geração a que os participantes pertencem. Logo, no tocante à faixa etária dos acadêmicos, os dados coletados mostram que dos 16 discentes, 9 encontram-se na faixa etária entre 31 e 40 anos de idade, totalizando $56 \%$, e 6 discentes, na faixa etária de 21 a 30 anos, totalizando 38\% dos respondentes. Observa-se, também, que há um aluno cuja idade está entre 41 e 50 anos, com porcentagem de $6 \%$, conforme podemos observar no gráfico a seguir.

Gráfico 1 - Faixa etária dos sujeitos da pesquisa

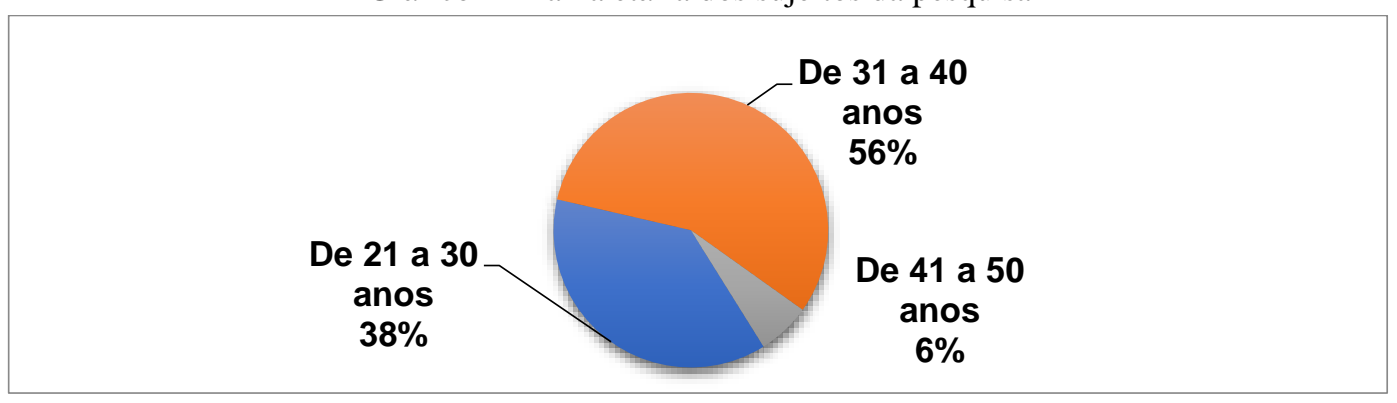

Fonte: Dados da pesquisa.

Os dados dos investigados revelam a predominância da faixa etária entre 31 e 40 anos, nascidos entre o final da década de 1970 e de 1980, que, segundo Oliveira (2006), configurouse como indivíduos de uma geração que presenciou os maiores avanços tecnológicos, logo consideram a tecnologia e seus recursos algo natural, e tem visão multifuncional e habilidade de ações simultâneas. Contudo, é fundamental pensarmos no fato de, possivelmente, os discentes não terem tido uma formação educacional fundamentada no uso de novas tecnologias de informação e comunicação. Talvez, esta tenha sido embasada no ensino tradicional.

Considerando o objetivo de nosso estudo, investigar o impacto das novas tecnologias na formação dos alunos de Letras, na modalidade Ensino Presencial Conectado, procuramos, primeiramente, saber qual a concepção deles sobre multiletramento. Assim, ao analisarmos as respostas dos alunos, observamos terem se dividido, de modo geral, em duas concepções: (1) 
capacidade de ler, interpretar, com a diversidade de linguagens e a compreensão da leitura e da escrita ; (2) direcionada às variedades de gêneros.

Tais enunciações podem ser sintetizadas no gráfico a seguir:

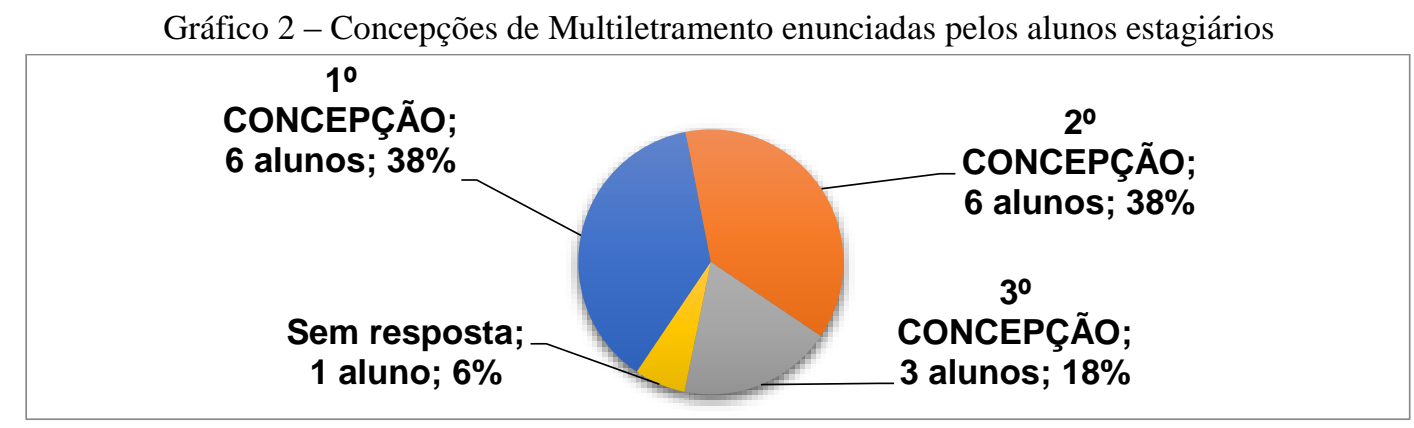

Fonte: Dados da pesquisa.

A primeira concepção, constatada a partir das respostas de 6 alunos, totalizando 37\%, foi: "o multiletramento se relaciona à capacidade de ler, interpretar, com a diversidade de linguagens e a compreensão da leitura e da escrita". As respostas enunciadas nessa primeira concepção de letramento foram as seguintes:

A1: Multiletramento é a capacidade do indivíduo saber ler, interpretar, argumentar as diferentes modalidades de leitura e escrita ofertados pela sociedade.

A2: São as várias formas de ler o mundo. É estar antenado e saber decifrar, criticar, analisar os diversos gêneros expostos na sociedade.

A3: Diversidade de linguagens, ler, escrever e compreender o que lê e escreve.

A4: Diversidade de linguagens.

A5: São as formas de trabalhar com a leitura em sala de aula, a partir de uma diversidade de linguagens.

A6: É o ato de ler, entender, articular diferentes modalidades de linguagem além da escrita, como a imagem, a fala e a música.

As proposições dos sujeitos estão adequadas. A1 destaca: "saber ler, interpretar"; A2 enuncia que "são várias formas de ler o mundo [...] estar antenado e saber decifrar, criticar, analisar"; A4 cita as várias linguagens, com ênfase no ato de "ler, escrever e compreender" os sentidos dos textos enunciados e lidos; A5 compreende que multiletramento está interligado às "várias formas de trabalhar com a leitura em sala de aula", inclusive cita que esse trabalho deve abordar "uma diversidade de linguagens". A6 corrobora tratar-se de uma ação, pois defende ser "o ato de ler, entender, articular" e finaliza destacando as "diferentes modalidades de linguagem". É interessante que A6 é o único a pensar em multiletramento "além da escrita", englobando "imagem, fala e música", ou seja, os diferentes textos semióticos, conforme pontuado por Rojo (2012), visto existirem, na sociedade, múltiplas práticas letradas. 
Assim, essa primeira concepção de multiletramento proferida pelos alunos de que se relaciona à capacidade de ler, interpretar, com a diversidade de linguagens e a compreensão da leitura e da escrita, é oportuno considerar o entendimento de Rojo (2004, p.31) sobre esse conceito, visto que a autora assevera que se trata de "compreender e produzir textos não se restringe ao trato do verbal oral e escrito, mas à capacidade de colocar-se em relação às diversas modalidades de linguagens — oral, escrita, imagem, imagem em movimento, gráficos, infográficos, etc. — para delas tirar sentido".

Já a segunda concepção a respeito de multiletramento é enunciada por 6 sujeitos, totalizando $38 \%$, e foi direcionada às variedades de gêneros textuais/discursivos, conforme podemos constatar a partir das respostas elencadas:

A7: Variedades de gêneros digitais (tecnologia).

A8: São os vários tipos de gêneros digitais. As várias formas de letramento que temos na atualidade.

A9: São as diversas formas de um indivíduo conseguir realmente e tecnologicamente transpor seus saberes de leitura e escrita perante a sociedade, considerando o gênero e a instância que está inserido ${ }^{l}$.

A10: São as várias formas tecnológicas de busca do conhecimento via gêneros.

A11: Aprender através de gêneros digitais multimodais.

A12: É quando o cidadão consegue entender e utilizar as várias ferramentas de ensino, inclusive as tecnológicas, e através disso participar dos vários gêneros discursivos e se inserir efetivamente na sociedade.

Os dados indicam que a leitura dos gêneros apresentada está em consonância com o a presença da multimodalidade, concretizada por meio das multissemioses (imagem estática ou em movimento, som, linguagem escrita). As proposições de A7 ("gêneros digitais"), A8: ("gêneros digitais"), A10 ("várias formas tecnológicas") e A11 ("gêneros digitais multimodais"), tais vozes reverberam os estudos de Santaella (2007), nos quais a autora defende o trabalho com o multiletramento em ambiente digital.

Já as proposições de A9 e A12 são mais voltadas para a adequação do gênero à esfera de atividade humana. Contudo, a ideia de "transpor seus saberes de leitura e escrita" para a leitura dos gêneros digitais talvez não seja a mais indicada, visto que não se trata de transpor um saber, mas sim de compreender a relativa instabilidade dos gêneros, acessar novos e diferentes saberes, pois “já não há lugar, nenhum ponto de gravidade de antemão garantido para qualquer linguagem, pois todas entram na dança das instabilidades" (SANTAELLA, 2007, p. 24).

\footnotetext{
${ }^{1}$ Apesar de essa resposta considerar multiletramento como saberes de leitura e escrita, optamos por deixá-la na $2^{\mathrm{a}}$ concepção, ligada às variedades de gêneros textuais/discursivos.
} 
Então, essa segunda concepção de multiletramento esboçada pelos discentes relacionao às variedades de gêneros textuais/discursivos e pode ser enriquecida a partir das ideias de Rojo e Moura (2012):

Trabalhar com multiletramentos pode ou não envolver (normalmente envolverá) o uso de novas tecnologias de comunicação e de informação (novos letramentos), mas caracteriza-se como um trabalho que parte das culturas de referência do alunado (popular, local, de massa) e de gêneros, mídias e linguagens por eles conhecidos, para buscar um enfoque crítico, pluralista, ético e democrático - que envolva agência de textos/discursos que ampliem o repertório cultural, na direção de outros letramentos, valorizados ou desvalorizados (ROJO; MOURA, 2012, p. 8).

Os dados indicaram, ainda, três outras respostas, totalizando $19 \%$, que fogem das concepções de multiletramento enunciadas pelos demais alunos:

A 13: É o nome dado às muitas modalidades de textos em que uma pessoa utiliza e interage através dos vários meios de suportes, como: a internet, páginas sociais, blogs.

A14: Um conjunto de não só um, mas muitos sendo ensinados de forma mais densa.

A15: São as diversas formas de aprendizado como as tradicionais e as novas como internet, navegar na web, etc.

A enunciação de A14 é vaga, indicando dificuldade de definir o solicitado. Já nos demais, a ênfase foi direcionada ao suporte e às ferramentas nele existentes, como é o caso de A13 ("vários meios de suportes, como: internet, páginas sociais, blogs") e A15 ("internet, navegar na $w e b ")$, o que nos conduz as proposições de Lévy (1996) sobre a cibercultura dispor de um imensurável espaço virtual no qual são alocados inúmeros gêneros, objetos virtuais, cabendo ao leitor digital atentar para os caminhos a serem trilhados de forma a não se desviar dos objetivos propostos.

Cabe destacar que dentro do universo de 16 sujeitos, um não respondeu a questão: talvez, por sentir-se inseguro quanto ao assunto investigado, visto que deixou em branco.

Outra questão investigada foi sobre a compreensão dos discentes a respeito do impacto das novas tecnologias na prática docente.

A1: Uma ferramenta para ajudar o professor no ensino e na prática pedagógica.

A2: De grande importância, já que vivemos em um mundo onde a geração atual está inserido na cultura tecnológica. Adaptá-las à educação é um instrumento de apoio que irá trazer um ambiente interativo, lúdico e atrativo para o aprendizado.

A3: Ótimas, mas muito difícil de colocá-las em prática.

A4: De grande importância e necessária, tanto para o docente, como para o aluno, pois o docente só terá interesse mediante o progresso dos alunos.

A5: Importante, pois, cada vez mais, os jovens da atualidade se adaptam aos novos meios de informações, portanto, o professor precisa estar cada vez mais bem informado. 
A6: Eu acredito que as novas tecnologias são de grande ajuda na prática docente, uma vez que pode tornar as aulas mais atraentes, o que prende a atenção dos alunos e torna a aula mais produtiva.

A7: De forma positiva, uma vez que sabendo usá-la trará muitos benefícios para o aluno e o professor.

A8: Algo essencial, visto que para os nativos digitais isso é algo do cotidiano e, para que possam se sentir atraídos, temos que entrar nessas novas práticas, as quais tendem a nos ajudar ainda mais em nosso trabalho.

A9: Avalio como um instrumento que será muito utilizado positivamente para a contribuição do ensino aprendizagem.

A10: De forma positiva, pois o avanço tecnológico é uma realidade.

A11: Tem tudo para ajudar e evoluir na educação, que por sinal está muito defasada.

A12: Será inovador, porém um desafio ao docente para a prática em sala de aula.

A13: Uma forma de fazer um aprendizado mais acelerado de forma mais prática.

A14: Ótimo, uma vez que acompanha e facilita ao professor o ministrar as aulas, tendo em vista os diversos recursos que dispõe.

A15: Positiva, desde que atinja o objetivo comum aos tradicionais, sendo inovado somente o canal do conhecimento.

A16: Penso que é positivo, uma vez que, independentemente da época, as pessoas devem utilizar sempre os recursos contemporâneos. Somente assim, é possível a vivência escola-cotidiano.

Observa-se que os alunos, em sua totalidade, consideram que as novas tecnologias têm uma grande importância enquanto instrumento facilitador da aprendizagem, embora alguns não sejam nativos digitais.

As respostas dos alunos indicam terem uma percepção do uso das tecnologias de informação e comunicação bem diversificada. A seguir, elencamos as proposições afins: A1: "A tecnologia ajuda no ensino e na prática pedagógica."; A2: "A tecnologia é um instrumento de apoio, interativo, lúdico e atrativo para o aprendizado."; A4: "O docente só terá interesse mediante o progresso dos alunos."; A6: "Torna as aulas mais atraentes, prende a atenção dos alunos e torna a aula mais produtiva."; A7: "Traz benefícios para o aluno e o professor."; A8: "Ajuda em nosso trabalho."; A9: "Contribui com o ensino e a aprendizagem.”; A10: "Avanço tecnológico é uma realidade."; A11: “Ajuda a evoluir a educação.”; A13: "Faz o aprendizado mais acelerado e de forma mais prática."; A14: "Facilita ao professor o ministrar as aulas."; A15: Deve atingir o objetivo comum aos tradicionais, sendo inovado somente o canal do conhecimento.”; A16: "Devemos utilizar sempre os recursos contemporâneos".

Nessas enunciações a ênfase é direcionada foi ao fato de a tecnologia auxiliar, ser um instrumento capaz de tornar a aula mais dinâmica, prazerosa, conferir à aula um caráter mais contemporâneo, atual. Contudo, é relevante "não nos esquecermos de que a tecnologia possui um valor relativo: ela somente terá importância se for adequada para facilitar o alcance dos 
objetivos e se for eficiente para tanto", logo "as técnicas não se justificarão por si mesmas, mas pelos objetivos que se pretenda que elas alcancem, que no caso serão de aprendizagem (MORAN; MASETTO; BEHRENS, 2000, p. 144).

Assim, o papel do professor continua sendo essencial nesse contexto. Da mesma forma, não se trata de usar a tecnologia como pretexto para o ensino, ela precisa estar inserida em objetivos claros que tenham um entrelaçamento com competências e habilidades a serem desenvolvidas.

As proposições de A3 ("O uso da tecnologia é difícil de pôr em prática.”), A5 ("O professor precisa estar cada vez mais bem informado.") e A12 ("Um desafio ao docente para a prática em sala de aula.") assumem o desafio desse trabalho na esfera escolar, visto que, nas palavras de Mercado (2002, p.12), “as instituições educacionais enfrentam o desafio não apenas de incorporar as novas tecnologias como conteúdos do ensino", mas, ir, além, pois elas devem "reconhecer as concepções que os aprendizes têm sobre estas tecnologias para elaborar, desenvolver e avaliar práticas pedagógicas que promovam o desenvolvimento de uma disposição reflexiva sobre os conhecimentos e os usos tecnológicos".

Isso posto, nas proposições dos sujeitos e nas asserções de Mercado (2002), reverberam vozes que indicam haver uma lacuna entre querer e poder trabalhar com a tecnologia na escola. Essa questão perpassa fatores, por exemplo, desde ter acesso a equipamentos adequados, como ter conexão com bom funcionamento, além, naturalmente, do letramento digital para o docente/estagiário.

A seguir, pesquisamos sobre os recursos tecnológicos disponíveis nas escolas públicas da cidade de Montes Claros-MG, locais onde os sujeitos fizeram o Estágio Curricular Obrigatório. Essa questão foi contemplada devido ao fato de os acadêmicos vivenciarem novas experiências durante o período de Estágio Acadêmico Curricular, no qual deviam utilizar novos recursos, aos quais tiveram acesso nas disciplinas, em sua prática discente. As respostas a respeito dos recursos foram:

A1: TV pendrive, data show, conexão sem fio, sala de vídeo, laboratório de informática.

A2: TV pendrive, lousa digital, retroprojetor, data show, conexão sem fio, sala de vídeo, laboratório de informática, internet banda larga, DVD, aparelho de som.

A3: TV pendrive, data show, sala de vídeo, internet banda larga.

A4: Sala de vídeo, laboratório de informática.

A5: TV pendrive, data show, sala de vídeo, laboratório de informática.

A6: Data show, sala de vídeo, laboratório de informática. 


\section{A7: Laboratório de informática}

A8: Data show, sala de vídeo, laboratório de informática.

A9: TV pendrive, data show, sala de vídeo, internet banda larga.

A10: Data show, sala de vídeo, laboratório de informática

A11: Data show, sala de vídeo, laboratório de informática.

A12:TV pendrive, data show, sala de vídeo, laboratório de informática, internet banda larga.

A13: TV pendrive, lousa digital, datashow, conexão sem fio, sala de vídeo, laboratório de informática, internet banda larga.

A14: TV pendrive, TV Paulo Freire, data show, conexão sem fio, sala de vídeo, laboratório de informática, internet banda larga.

A15: Data show, conexão sem fio, sala de vídeo.

A16: TV pendrive, lousa digital, data show, conexão sem fio, sala de vídeo, laboratório de informática, internet banda larga.

Analisando os dados, temos o seguinte resultado: a sala de vídeo foi a mais citada, ou seja, dos 16 sujeitos, 15 citaram-na. Em seguida, 14 alunos asseveraram que nas escolas havia data show e 13 alunos, que a escola disponibilizava de um laboratório de informática.

Os estudantes explicitaram que, também, encontraram outros recursos, a saber: TV pendrive ( 9 alunos), internet banda larga (7 alunos) e conexão sem fio (6 alunos). Finalmente, identificaram a lousa digital (3 alunos), retroprojetor manual, aparelho de $D V D$ e aparelho de som, estes com apenas a identificação de um aluno.

Observa-se que o sinal adequado da internet ainda é um problema para o uso da tecnologia na escola, pois somente 7 sujeitos conseguiram trabalhar adequadamente. Lévy (1996) aponta que ser necessário ter uma estrutura na velocidade da conexão da internet para haver uma navegação no espaço virtual com conexões rápidas e qualidade adequada de imagem/som/movimento adequada.

Podemos concluir, seguindo as indicações dos alunos, que alguns equipamentos são mais frequentes do que outros nas escolas de Montes Claros-MG, posto uns serem mais citados e outros, menos. Em vista disso, apresentamos o gráfico a seguir, sintetizando o resultado dos dados coletados. 
Gráfico 3 - Recursos tecnológicos disponíveis nas escolas públicas de Montes Claros-MG

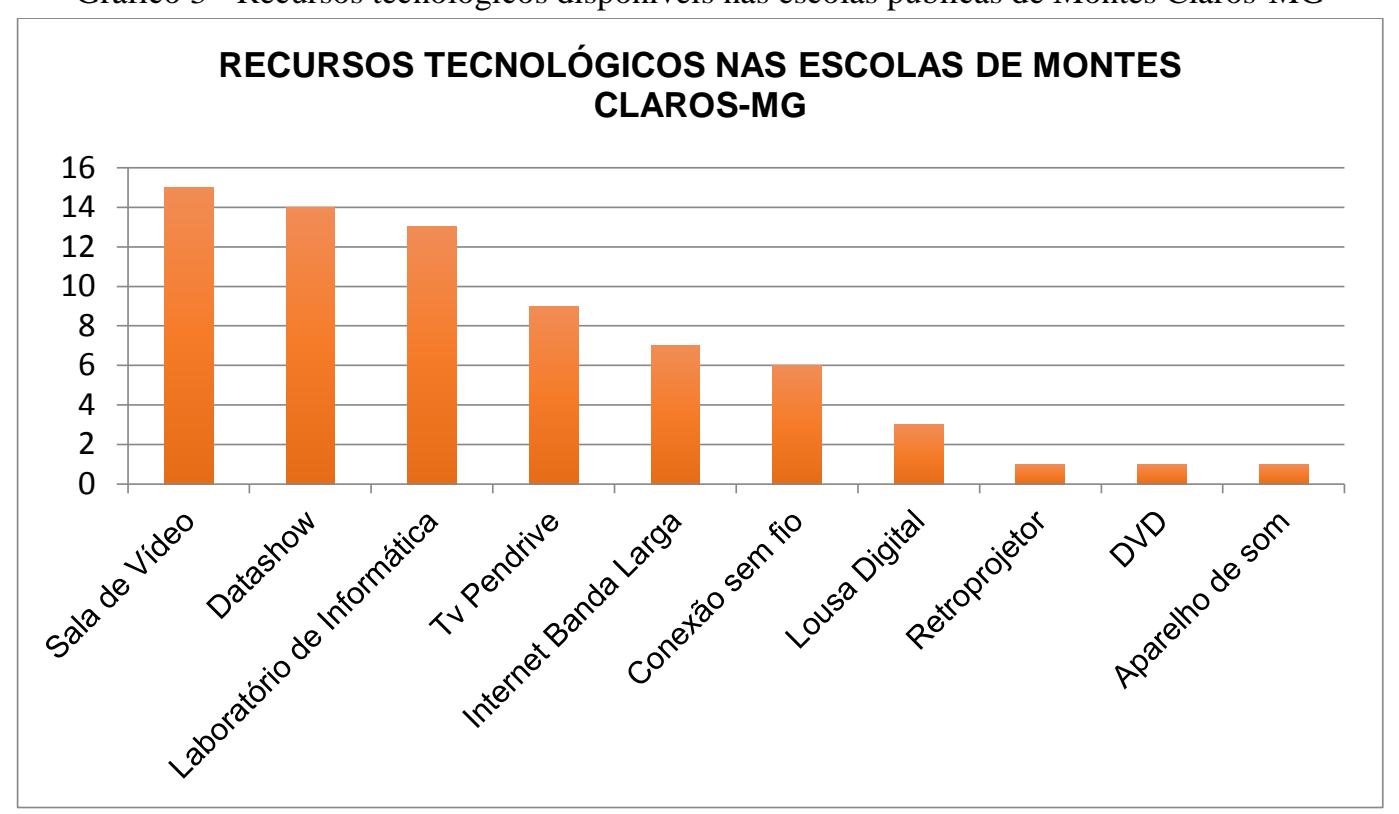

Fonte: Dados da pesquisa.

Concluímos, por meio da leitura do gráfico, que as escolas da região investigada estão parcialmente providas de recursos tecnológicos. Uma justificativa de terem sido menos citados o retroprojetor tradicional, o aparelho de DVD e o aparelho de som dever-se ao fato de outros equipamentos terem mesma função. Por exemplo, no caso do retroprojetor, este praticamente encontra-se em desuso onde há data show, logo são ferramentas que podem ter sido trocadas por outras mais atuais, como o data show e a tv pendrive.

No tocante a se os entrevistados utilizaram, durante o Estágio Curricular Obrigatório, os equipamentos disponíveis nas escolas, verificamoss que 1 aluno $(6,25 \%)$ não fez uso de nenhum equipamento; 4 alunos (25\%) afirmaram terem tido contato com todos os equipamentos; os outros 11 (68,75\%), ou seja, a maioria, reconheceu não terem feito uso, apenas, da lousa digital e apenas um participante não usou a TV pendrive. Logo, os demais equipamentos foram explorados, com exceção da navegação na internet, pois dependia de conexão.

Em relação ao alto índice da não utilização da lousa digital, inferimos que se deve ao fato de, em algumas escolas, não estar disponível. Mesmo na única escola em que havia, o sujeito asseverou não ter feito uso dela, o que pode estar relacionado ao fato do despreparo do estagiário para o manuseio desse equipamento.

O público de nossas escolas lida com estes aparatos de forma natural e constante e, segundo o gráfico anterior, a escola dispõe dos equipamentos que fazem parte do cotidiano dessa geração. Porém, cabe ao professor utilizá-los de forma a colaborar para o 
desenvolvimento do aluno enquanto sujeito crítico, consciente e autônomo, e não apenas inserir a tecnologia como forma de diversão, mantendo o ensino engessado, ainda comum nas salas de aula.

A próxima questão avalia os entrevistados sobre o pensamento deles a respeito do preparo do professor para usar a tecnologia em sala de aula. Coletamos os seguintes dados:

A1: Não. Pois a maioria das instituições de ensino não oferece as ferramentas necessárias para o professor se especializar e usá-las.

A2: Não. O pensamento está ainda muito engessado na educação tradicional e os professores, sem preparo.

A3: Não. Por não conhecer e saber manusear os aparelhos disponíveis.

A4: Sim, e quem não está, com certeza, está em busca, pois a tecnologia tomou conta do mundo.

A5: Sim. Porque a maioria das pessoas de certa forma tem contato indiretamente. É só fazer um esforço e se atualizar nos planos de aula.

A6: Sim. Porque hoje todo mundo utiliza a tecnologia e, para utilizar em sala de aula, é só adequar à disciplina.

A7: Não. Porque eles não devem ser usados de qualquer maneira.

A8: Não. Há necessidade de aperfeiçoamento, haja vista que ouvi de professores que isso atrasaria o andamento das aulas.

A9: Não. Nem todos professores têm uma preparação para estar totalmente apto para saber trabalhar com todos os instrumentos tecnológicos.

A10: Não. Devido à falta de treinamento e de estímulo por parte dos responsáveis.

A11: Não. *Sem justificativa.

A12: Não. Porque falta interesse dos docentes em relação ao ensino com uso de tecnologias.

A13: Sim. Ele já passou pelo estado “aluno” e compreende bem como funciona.

A14: Sim. * Sem justificativa.

A15: Não. Falta de atualização.

A16: Não. Porque muitos ainda resistem em utilizar a tecnologia por medo ou comodismo.

A partir da análise identificamos que 11 alunos, ou seja, 69\%, alegaram que os professores não estão preparados, contra $31 \%$, representados por 5 alunos.

Gráfico 4 - O professor está preparado para usar a tecnologia em sala de aula?

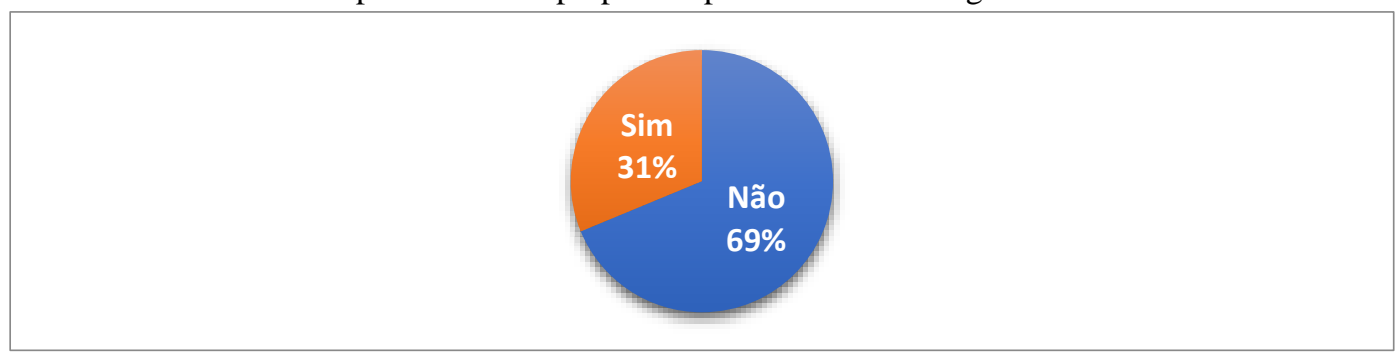

Fonte: Dados da pesquisa. 
Dos 69\% (11 alunos) que afirmaram que os professores não estão preparados, consideramos válido destacar as seguintes respostas: "Não. Pois a maioria das instituições de ensino não oferece as ferramentas necessárias para o professor se especializar e usá-las."; "Não. O pensamento está ainda muito engessado na educação tradicional e os professores sem preparo."; "Não. Nem todos professores têm uma preparação para estar totalmente apto para saber trabalhar com todos os instrumentos tecnológicos."; "Não. Devido à falta de treinamento e de estímulo por parte dos responsáveis"; "Não. Porque falta interesse dos docentes em relação ao ensino com uso de tecnologias."; "Não. Porque muitos ainda resistem em utilizar a tecnologia por medo ou comodismo".

As respostas dos 5 alunos (31\%) que apontam positivamente para o preparo do professor na utilização das novas tecnologias em aulas, na verdade, atestam que os professores têm o conhecimento de estas serem presentes no dia a dia da sociedade, mas não deixam claro se estão preparados para utilizá-las na prática do ensino, conforme observamos nas respostas: "Sim, e quem não está, com certeza, está em busca, pois a tecnologia tomou conta do mundo."; "Sim. Porque a maioria das pessoas de certa forma tem contato indiretamente. É só fazer um esforço e se atualizar nos planos de aula"; "Sim. Porque hoje todo mundo utiliza a tecnologia e para utilizar em sala de aula é só adequar à disciplina.”; “Sim. Ele já passou pelo estado 'aluno' e compreende bem como funciona."; uma resposta apresenta apenas "sim", sem justificá-lo.

Após a análise, podemos afirmar que o professor tem consciência de que as tecnologias já fazem parte do contexto de comunicação da sociedade, mas não sabe como adequá-las à sala de aula. Pelas enunciações, parece faltar formação para esse professor, visto alegarem que inexiste um formação mais voltada para o uso dos recursos tecnológicos disponíveis. Logo, trabalhar com a tecnologia pode resultar em algo dificultoso ao professor. Resultado similar foi encontrado na publicação dos estudos de Martín et al (2016), no qual os pesquisadores da Universidade de Salamanca (Espanha) relatam que investigaram 198 professores do ensino primário e secundário, tendo como foco a questão da aprendizagem colaborativa, realizada por meio da exploração das Tecnologias da Informação e Comunicação. Segundo Martín et al (2016, p. 194), o resultado apontou que "Praticamente todos os professores $(98,1 \%)$ são claros que as TICs agregam valor", todavia "apenas metade deles (53\%) os usa para desenvolver esse tipo de trabalho com seus alunos". Assim, notamos que a correlação entre a mobilização de saberes sobre tecnologia pelos discentes depende da mobilização desses saberes agenciados pelos docentes. 
Retomando nossa análise, outras enunciações indicam que pode também haver certo comodismo, por parte do professor, assim ele tende a optar por reproduzir modelo pedagógico já estabelecido. Logo, faz-se necessário, portanto, despertar e incentivar o professor para o uso das TICs em sala de aula, de forma consciente, a fim de provocar o desenvolvimento do aluno, tornando-o coautor da sua aprendizagem e focando na formação da sua autonomia. Oportunamente, Rojo (2012) alerta:

Vivemos em um mundo em que se espera (empregadores, professores, cidadãos, dirigentes) que as pessoas saibam guiar suas próprias aprendizagens na direção do possível, do necessário e do desejável, que tenham autonomia e saibam buscar como e o que aprender, que tenham flexibilidade e consigam colaborar com urbanidade (ROJO, 2012, p. 27).

Nessas asserções vemos o revozeamento das proposições defendidas por Soares (2002) e Santaella (2007), no que tange à necessidade, tanto do professor quanto do aluno, de buscarem os novos saberes necessários, diante das mudanças impulsionadas por uma sociedade na qual eclodem os textos pluri e multimodais, dentro de uma cultura pluri e multidiversificada.

\section{CONSIDERAÇÕES FinAIS}

O objetivo do presente artigo foi averiguar o impacto das novas tecnologias na formação discente, mais especificamente no Estágio Curricular Obrigatório, dos alunos de Letras, na modalidade Ensino Presencial Conectado. Investigamos a percepção sobre multiletramento e a utilização das novas tecnologias em âmbito escolar, procurando associar teoria e prática no tocante à Educação e à Tecnologia. Para tanto, procedemos uma pesquisa, por meio do instrumento questionário, junto aos alunos concluintes do curso de Letras de uma universidade particular do estado de Minas Gerais, que, em síntese, retrata uma visão de consciência do professor da presença da tecnologia na comunicação social, porém este ator, não sabe como adequá-las ao contexto educacional, usando-as enquanto ferramentas de ensino.

Dessa forma, os resultados podem ser sintetizados nas seguintes asserções: (a) os futuros professores representam uma geração que presenciou os avanços tecnológicos, convivem e fazem uso das novas tecnologias, contudo, estas, não fizeram parte da formação educacional; (b) com relação ao conceito de multiletramento, uma minoria fugiu da concepção correta, porém, foram observadas duas concepções: a primeira relacionada à capacidade de ler, interpretar, com a diversidade de linguagens e a compreensão da leitura e da escrita, e a segunda, às variedades de gêneros textuais; (c) na sua totalidade, os entrevistados consideram que as novas tecnologias têm uma grande importância enquanto instrumento facilitador da aprendizagem, entretanto, quanto ao uso destas, apresentam percepções diversificadas; (d) no 
que se refere aos recursos ou tipos de ambientes disponíveis nas Escolas Públicas da cidade de Montes Claros (MG), concluímos que as escolas da região estão providas de recursos tecnológicos, organizados dos mais aos menos citados: sala de vídeo, data show, laboratório de informática, TV pendrive, internet banda larga, conexão sem fio, lousa digital, retroprojetor, DVD, aparelho de som; (e) quanto ao contato dos estagiários com os equipamentos tecnológicos, concluímos que procuraram fazer uso dos equipamentos disponíveis nas escolas, os recursos não utilizados, em sua maioria, não estavam disponíveis no período de estágio. A lousa digital disponível em uma escola e não utilizada pelo estagiário pode ser resultado da falta de preparo para o manuseio; (f) a respeito do preparo do professor na utilização da tecnologia na sala de aula, 11 alunos (69\%) alegaram não estarem preparados, contra 5 alunos (31\%) que responderam positivamente, mas suas respostas, na verdade, atestam que os professores têm conhecimento da presença das novas tecnologias no cotidiano, mas não deixam explícito o preparo para a utilização na sala de aula.

Assim, mediante o exposto, depreende-se que existe a consciência, por parte dos docentes, sobre a relevância do uso da tecnologia no contexto educacional. Talvez o que falte tenha a ver com a questão da instrumentalização, do sentir-se apto e seguro para desenvolver uma ação. Cursos que apontem para esse professor como esse uso, efetivamente, podem o auxiliar no desenvolvimento das atividades, de tal forma que ele se sinta seguro para, cada vez mais, romper com a reprodução da sua prática docente tradicional e ousar inserir ferramentas tecnológicas mediadoras entre o aluno e o conhecimento. E isso se efetivará quando a tecnologia contemplar o Projeto Político Pedagógico da Escola, o Plano de Aula e, consequentemente, a prática pedagógica do professor.

\section{REFERÊNCIAS}

BAKHTIN, Mikhail M. Estética da criação verbal. 5. ed. São Paulo: WMF Martins Fontes, 2010.

CARMO, Josué G. Botura. O letramento digital e a inclusão social. 2003. Disponível em: $<$ https://sites.google.com/site/estudosdeletramento/letramento-digital-1>. Acesso em: 25 out. 2017.

CRUZ, Vilma Aparecida Gimenes. Metodologia da pesquisa científica. São Paulo: Pearson Prentice Hall, 2009.

FREGONEZE, Gisleine Bartolomei; TRIGUEIRO, Rodrigo de Menezes; RICIERI, Marilucia; BOTELHO, Joacy Machado. Metodologia científica. Londrina: Editora e Distribuidora Educacional, 2014.

LÉVY, Pierre. O que é virtual?. Tradução de Paulo Neves. São Paulo: Ed. 34, 1996. 
MARTÍN, Sonia Casillas; GONZÁLEZ, Marcos Cabezas; ARRIBA, Jorge Martín de. Knowledge Management: Experiences of Collaborative Work Using ICT with Students. Digital Educaction Review, v. 30, p. 184-206, 2016. Disponível em: <http://revistes.ub.edu/index.php/der/article/view/15075>. Acesso em: 05 mar. 2018.

MERCADO, Luís Paulo Leopoldo. Formação docente e novas tecnologias. In: Luiz Paulo Leopolto (Org.). Novas tecnologias na educação: reflexões sobre a prática. Maceió: Edufal, 2002.

MORAN, José Manuel; MASETTO, Marcos T.; BEHRENS, Marilda Aparecida. Novas tecnologias e mediação pedagógica. Campinas: Papirus, 2000.

NANTES, Eliza. Língua portuguesa II: leitura e produção de texto. São Paulo: Pearson Prentice Hall, 2009.

OLIVEIRA. Fátima Bayma de. Tecnologia da Informação e Comunicação: A busca de uma visão ampla e estruturada. São Paulo: Pearson, 2006.

RAMPAZZO, S. R. R.; FRANÇA, C. S.; BADALOTTI, G. M.; FAVERE, J. Educação e tecnologias. Londrina: Editora e Distribuidora Educacional, 2014.

ROJO, R. H. R. Linguagens Códigos e suas tecnologias. In: BRASIL. Ministério da Educação. Secretaria da Educação Básica. Departamento de Políticas do Ensino Médio. Orientações curriculares do ensino médio. Brasília, 2004.

ROJO, Roxane; MOURA, Eduardo. Multiletramentos na escola. São Paulo: Parábola, 2012.

SANTAELLA, L. Linguagens líquidas na era da mobilidade. São Paulo: Paulus, 2007.

SILVA, Solimar Patriota. Letramento digital e formação de professores na era da web 2.0: o que, como e por que ensinar?. Hipertextus Revista Digital, n. 8, jun. 2012. Disponível em: $<$ http://doczz.com.br/doc/647405/letramento-digital-e-forma\%C3\%A7\%C3\%A3o-deprofessores-na-era-da-we...>..Acesso em: 15 set. 2017.

SOARES, M. B. Novas Práticas de Leitura e Escrita: letramento na cibercultura. Educ. Soc., Campinas, v. 23, n. 81, p. 143-160, dez. 2002. Disponível em: <http://www.scielo.br/pdf/es/v23n81/13935.pdf>. Acesso em: 30 set. 2017.

SOARES, M. B. Letramento: um tema em três gêneros. Belo Horizonte: Autêntica, 2004. TFOUNI, L.V. Letramento e alfabetização. São Paulo: Cortez, 1995.

XAVIER, Antônio Carlos dos Santos. Leitura, texto e hipertexto. In: MARCUSCHI, L.A. (Orgs.). Hipertexto e gêneros digitais: novas formas de construção de sentido. Rio de Janeiro: Lucerna, 2004.

XAVIER, Antônio Carlos dos Santos. Letramento digital e ensino. Núcleo de Estudos de Hipertexto e Tecnologia Educacional. 2015. Disponível em:

<http://www.nehte.com.br/artigos/Letramento-Digital-Xavier.pdf>. Acesso em: 19 dez. 2017.

Recebido em: 4 de janeiro de 2018 .

Aprovado em: 7 de março de 2018. 